\title{
Передача электронного возбуждения от TPD к нанокристаллам $\mathrm{CdSe} / \mathrm{CdS} / \mathrm{ZnS}$
}

\author{
(C) Н.С. Курочкин ${ }^{1,2}$, А.В. Кацаба ${ }^{1,3}$, С.А. Амброзевич ${ }^{1,3}$, А.Г. Витухновский ${ }^{1,2}$, \\ А.А. Ващенко ${ }^{1}$, П.Н. Тананаев ${ }^{4}$ \\ ${ }^{1}$ Физический институт им. П.Н. Лебедева РАН, \\ 119991 Москва, Россия \\ ${ }^{2}$ Московский фризико-технический институт (государственный университет), \\ 141700 Долгопрудный, Россия \\ ${ }^{3}$ Московский государственный технический университет им. Н.Э. Баумана, \\ 125993 Москва, Россия \\ ${ }^{4}$ ВНИИА им. Н.Л. Духова, \\ 101000 Москва, Россия \\ E-mail: nikitakurochkin@mail.ru
}

(Получена 6 декабря 2016 г. Принята к печати 12 декабря 2016 г.)

Исследована эффективность передачи энергии электронного возбуждения от органического полупроводникового материала TPD к полупроводниковым нанокристаллам CdSe/CdS/ZnS, пассивированным различными органическими лигандами. Показано, что с увеличением толщины слоя пассиватора скорость передачи возбуждения от TPD к нанокристаллам уменьшается. Высказано предположение о ферстеровском механизме передачи возбуждения.

DOI: $10.21883 /$ FTP.2017.05.44424.8475

\section{1. Введение}

В 1993 году были впервые синтезированы полупроводниковые коллоидные нанокристаллы сферической геометрии (NCs) [1]. Эти объекты представляют огромный интерес, так как являются перспективными для создания фотонных и оптоэлектронных устройств нового поколения. Это обусловлено их уникальными свойствами: зависимостью длины волны излучения от размеров наночастиц, контролируемых в процессе синтеза, узкой полосой фотолюминесценции и возможностью их нанесения из жидкой фазы [2]. К настоящему времени на основе полупроводниковых нанокристаллов были созданы такие устройства, как органические светоизлучающие диоды (OLED) [3,4], фотовольтаические элементы [5], фотодетекторы [6] и перестраиваемые в видимом диапазоне лазеры [7].

Одним из факторов, влияющих на эффективность устройств фотоники на основе нанокристаллов, является скорость передачи электронного возбуждения как к нанокристаллам от окружающего их материала, так и между самими нанокристаллами. Например, в органических светоизлучающих диодах возможен перенос возбуждения к нанокристаллам от органического транспортного слоя $[8,9]$. Этот процесс определяет внутренний квантовый выход электролюминесценции этих устройств. В работе [10] показано, что изменение среднего расстояния между нанокристаллами в слое позволяет управлять длиной диффузии экситонов. В работе [11] исследован процесс передачи возбуждения полимера к нанокристаллам ядро/оболочка. В настоящей работе исследован процесс передачи энергии от органического флуоресцентного материала TPD(N,N'-bis(3-met-
hylphenyl)-N,N'-bis(phenyl)-benzidine), применяемого в органических светодиодах в качестве траспортного дырочного слоя, к нанокристаллам $\mathrm{CdSe} / \mathrm{CdS} / \mathrm{ZnS}$ с различным типом пассивирующих лигандов.

\section{2. Эксперимент}

Коллоидные нанокристаллы $\mathrm{CdSe} / \mathrm{CdS} / \mathrm{ZnS}$ со структурой ядро/оболочка/оболочка с двумя гетеропереходами I типа были синтезированы по методике, аналогичной представленной в работе [12]. В качестве стабилизаторов нанокристаллов были применены лиганды с изогнутой и линейной структурой: олеиламина $\left(\mathrm{C}_{18} \mathrm{H}_{35} \mathrm{NH}_{2}\right)$, молекула которого изогнута за счет двойной связи, а также линейных молекул - октан-1-тиол $\left(\mathrm{C}_{8} \mathrm{H}_{17} \mathrm{SH}\right)$ и додекантиола $\left(\mathrm{C}_{12} \mathrm{H}_{25} \mathrm{SH}\right)$. Покрытие октан-1-тиолом и додекантиолом осуществлялось путем замены исходного лиганда олеиламина при длительном перемешивании дисперсии исходных нанокристаллов в избытке соответствующего алкилтиола и последующей многократной очисткой наночастиц переосаждением спиртами. При проведении описанных процедур структурные свойства нанокристаллов оставались неизменными.

Размеры наночастиц были оценены с помощью программы ImageJ по результатам электронной микроскопии, проведенной с помощью просвечивающего электронного микроскопа JEOL JSM-7001F в ЦКП МФТИ. Передача электронного возбуждения была исследована на образцах, изготовленных с помощью центрифуги МТI TC100 Spin coater, а также накапыванием (drop-casting) растворов наночастиц и TPD в толуоле на предварительно очищенную стеклянную подложку. Толщина пленок могла варьироваться от десятков нанометров до одного 
микрометра в зависимости от способа нанесения. Концентрация TPD во всех растворах составляла $5 \mathrm{Mr} / \mathrm{cm}^{3}$, а нанокристаллов - порядка $10^{15} \mathrm{~cm}^{-3}$. Оценка концентрации наночастиц производилась согласно методике, описанной в работе [13].

Спектры фотолюминесценции были измерены с помощью спектрометра Ocean Optics Maya 2000 Pro при возбуждении излучением светодиода с длиной волны 365 нм. Измерение спектров поглощения и возбуждения было произведено с использованием спектрофотометра Perkin Elmer Lambda 45 и спектрометра СДЛ-1, где в качестве детектора использовался ФЭУ Hamamatsu Н6240-01, чувствительный в области 300-850 нм. Кинетические зависимости фотолюминесценции регистрировались с помощью конфокального флуоресцентного микроскопа PicoQuant MicroTime 200 методом коррелированного счета одиночных фотонов. В качестве источника возбуждения использовался полупроводниковый импульсный лазер PicoQuant LDH-375 (375 нм, 3.3 эB) с длительностью импульсов 50 пс и частотой следования 2.5 МГц. Размер области сканирования каждого образца составлял $80 \times 80$ мкм. Измерения проводились для образцов в пленках, а также в растворах в толуоле в специальных виалах при одинаковой интенсивности лазера в нескольких участках образца для обеспечения достоверности экспериментальных данных.

\section{3. Результаты и их обсуждение}

На рис. 1 представлены изображения нанокристаллов, полученные с помощью просвечивающего электронного микроскопа. Средние размеры $d$ нанокристаллов с учетом пассивирующего слоя составили $8.1 \pm 0.2$ нм для $\mathrm{NC} 1,8.3 \pm 0.2$ нм для $\mathrm{NC} 2,9.1 \pm 0.2$ нм для $\mathrm{NC} 3$. Стандартное отклонение размеров наночастиц составило около $1.3 \mathrm{HM}$.

На рис. 2 показаны спектры поглощения и фотолюминесценции пленок нанокристаллов NC1 и пленки TPD. Спектры нанокристаллов NC2 и NC3 имеют аналогичный вид, поскольку они отличаются лишь оптически неактивным пассиватором. Спектры поглощения нанокристаллов и спектр излучения TPD перекрываются, что говорит о возможности как излучательной, так и безызлучательной передачи возбуждения от TPD к наночастицам. У всех исследованных нанокристаллов имеется стоксов сдвиг около 50 мэВ. Значительная ширина полосы люминесценции (107 мэВ) обусловлена распределением наночастиц по размерам. На рис. 3 приведены спектры оптического возбуждения нанокристаллов NC1 и смеси TPD и NC1 при регистрации на длине волны 630 нм в максимуме спектра люминесценции наночастиц. Наличие полосы возбуждения в области 360 нм у смеси TPD и NC1 свидетельствует о передаче электронного возбуждения от TPD к нанокристаллам.

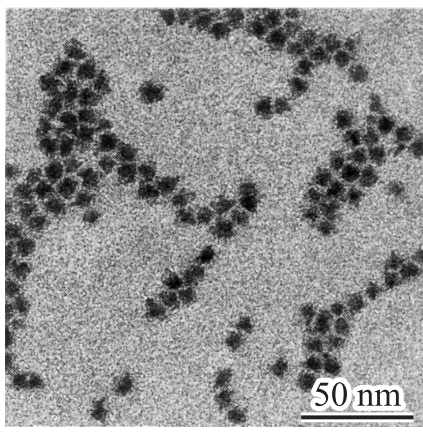

$\mathrm{NC} 1$
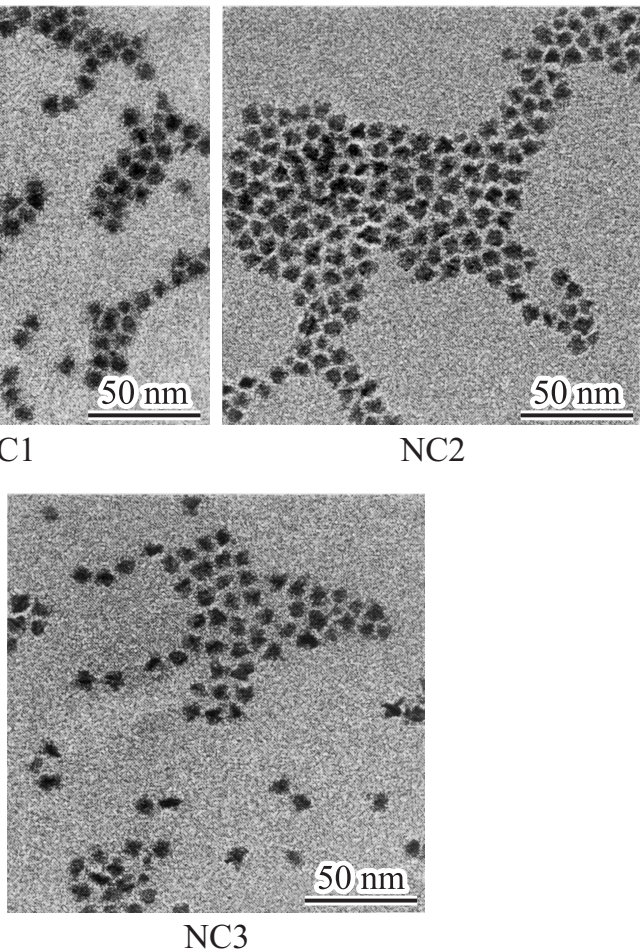

Рис. 1. Микрофотографии нанокристаллов $\mathrm{CdSe} / \mathrm{CdS} / \mathrm{ZnS}$ с различными типами пассивирующих лигандов: NC1 - с октан1-тиолом, средний размер частиц с учетом пассивирующего слоя $8.1 \pm 0.2 \mathrm{Hм}$; $\mathrm{NC} 2-$ с додекантиолом, средний размер частиц $8.3 \pm 0.2 \mathrm{Hм} ; \mathrm{NC} 3-$ олеиламина, средний размер $9.1 \pm 0.2 \mathrm{HM}$.

Кинетические зависимости фотолюминесценции пленки TPD и пленок из смеси TPD и нанокристаллов NC1, NC2 и NC3 соответственно представлены на рис. 4. Регистрацию сигнала фотолюминесценции производили в области свечения TPD в полосе $425 \pm 5$ нм, выделенной с помощью интерференционного светофильтра. Из полученных зависимостей видно, что в присутствии наночастиц релаксация люминесценции TPD происходит быстрее. При этом уменьшение среднего размера $d$ нанокристаллов увеличивает скорость релаксации люминесценции TPD. Кинетические зависимости имеют неэкспоненциальный характер; нормированные на единицу зависимости были аппроксимированы двухэкспоненциальной функцией

$$
I(t)=\alpha_{1} e^{-t / t_{1}}+\left(1-\alpha_{1}\right) e^{-t / t_{2}}
$$

с учетом свертки с аппаратной функцией $\operatorname{IRF}(t)$

$$
I_{\exp }(t)=\int_{-\infty}^{\infty} \operatorname{IRE}\left(t^{\prime}\right) I\left(t-t^{\prime}\right) d t^{\prime} .
$$

Здесь $\alpha_{1}$ и $\left(1-\alpha_{1}\right)-$ амплитуды, $t_{1}$ и $t_{2}-$ характерные времена релаксации экспоненциальных компонент, а $I_{\exp }(t)$ - экспериментально наблюдаемая кинетическая 


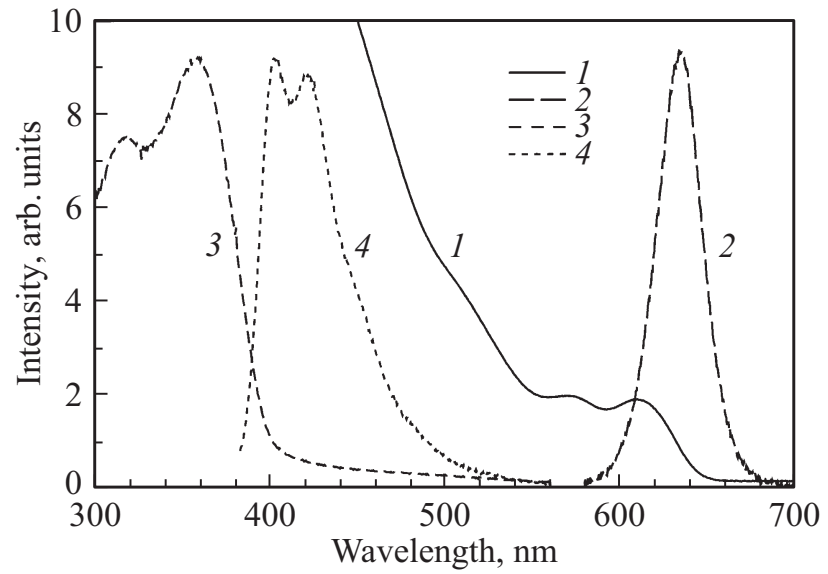

Pис. 2. Спектры поглощения и фотолюминесценции пленки нанокристаллов NC1 и пленки TPD. 1 - поглощение нанокристаллов, 2 - люминесценция нанокристаллов, 3 - поглощение TPD, 4 - люминесценция TPD.

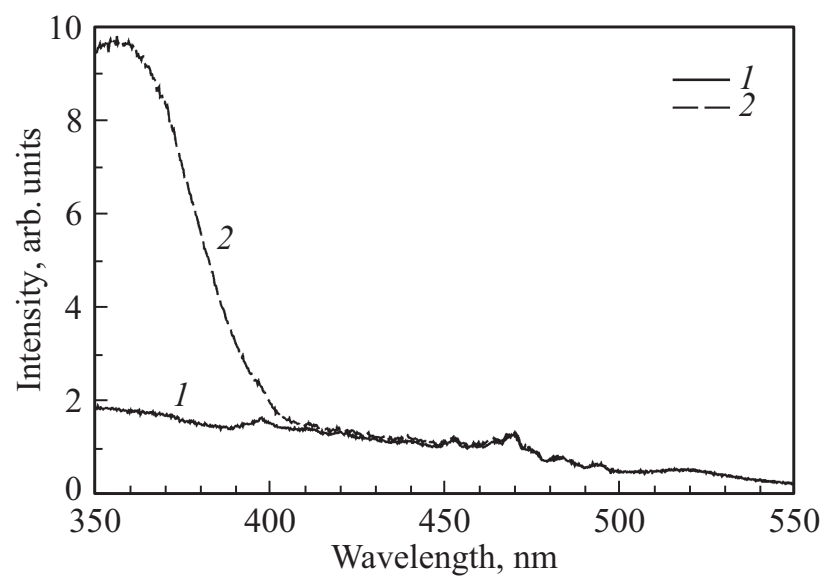

Рис. 3. Спектры оптического возбуждения пленки нанокристаллов NC1 (1) и пленки из смеси TPD и NC1 (2) при регистрации в области 630 нм.

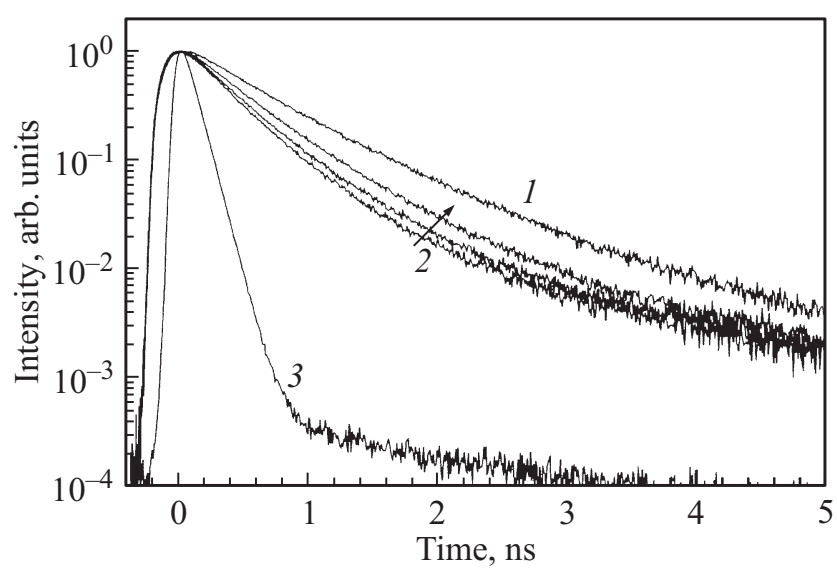

Рис. 4. Кинетические зависимости фотолюминесценции пленки TPD (1) и пленок из смеси TPD и нанокристаллов NC1, $\mathrm{NC} 2$ и NC3 (2), измеренные в области 425 нм. Стрелкой показано направление увеличения толщины пассиватора. Аппаратная функция прибора $\operatorname{IRF}(t)$ представлена зависимостью 3.

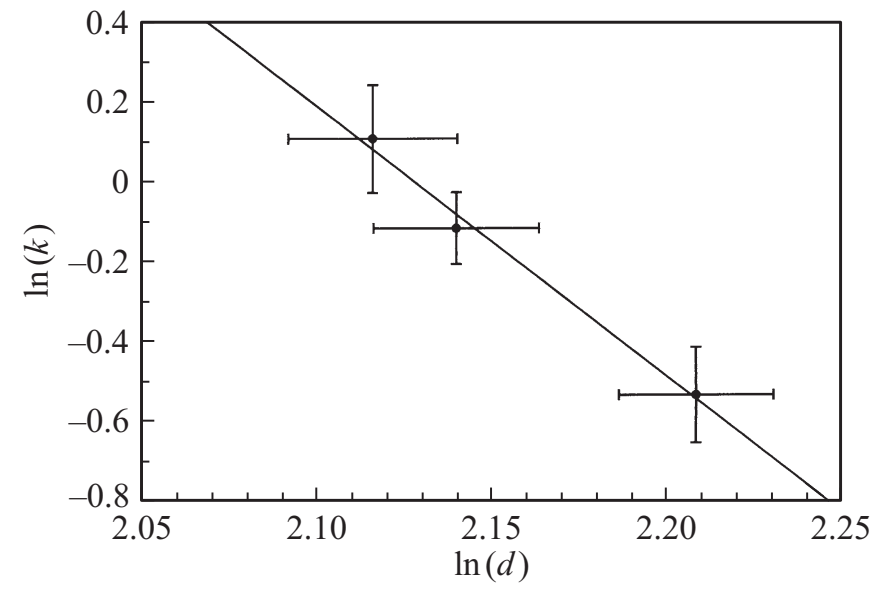

Рис. 5. Зависимость логарифма скорости переноса энергии $k\left[\mathrm{Hc}^{-1}\right]$ от TPD нанокристаллам NC1 от логарифма среднего размера $d[\mathrm{HM}]$ наночастиц. Также изображена наилучшая линейная аппроксимация.

зависимость. Результаты аппроксимации представлены в таблице. В качестве характеристики для оценки эффективности передачи электронного возбуждения от TPD к нанокристаллам было использовано среднее время релаксации

$$
\langle t\rangle=\alpha_{1} t_{1}+\left(1-\alpha_{1}\right) t_{2}
$$

Скорость передачи $k$ электронного возбуждения от TPD к нанокристаллам была оценена с помощью выражения

$$
k=\frac{1}{\langle t\rangle_{\mathrm{TPD}+\mathrm{NC}}}-\frac{1}{\langle t\rangle_{\mathrm{TPD}}},
$$

где и $\langle t\rangle_{\mathrm{TPD}}$ - время релаксации люминесценции TPD, $\langle t\rangle_{\mathrm{TPD}+\mathrm{NC}}$ - время релаксации смеси TPD и нанокристаллов.

Для известного механизма диполь-дипольной передачи электронного возбуждения зависимость $k$ от расстояния $R$ между донором и акцептором имеет вид $k \sim R^{-6}$ [14]. Зависимость $k$ от диаметра нанокристалла $d$ была аппроксимирована выражением $k \sim d^{\alpha}$ (рис. 5). При этом предполагалось, что электронное возбуждение в нанокристалле локализовано в его ядре размером около 4 нм. С учетом погрешности среднего диаметра наночастиц и времен релаксации $\alpha=-6.8 \pm 2.7$.

Результаты аппроксимации нормированных кинетических зависимостей с помощью формулы (1). Среднее время релаксации $\langle t\rangle$ было рассчитано согласно соотношению (3)

\begin{tabular}{c|c|c|c|c}
\hline & TPD & NC1 c TPD & NC2 c TPD & NC3 c TPD \\
\cline { 2 - 5 }$\alpha_{1}$ & $0.83 \pm 0.01$ & $0.90 \pm 0.02$ & $0.88 \pm 0.01$ & $0.85 \pm 0.01$ \\
$t_{1}, \mathrm{HC}$ & $0.51 \pm 0.01$ & $0.31 \pm 0.01$ & $0.33 \pm 0.01$ & $0.38 \pm 0.01$ \\
$t_{2}, \mathrm{HC}$ & $1.17 \pm 0.01$ & $0.91 \pm 0.03$ & $0.90 \pm 0.02$ & $0.92 \pm 0.02$ \\
$\langle t\rangle, \mathrm{HC}$ & $0.62 \pm 0.02$ & $0.37 \pm 0.02$ & $0.40 \pm 0.01$ & $0.46 \pm 0.01$
\end{tabular}


Это сопоставимо с $\alpha=-6$ для диполь-дипольной передачи энергии и указывает на наличие этого механизма. В нашем случае ферстеровский радиус равен 3.9 нм.

\section{4. Заключение}

В работе экспериментально продемонстрировано наличие процесса передачи электронного возбуждения от органического полупроводникового материала TPD к нанокристаллам $\mathrm{CdSe} / \mathrm{CdS} / \mathrm{ZnS}$. Показано, что с увеличением среднего расстояния $d$ между нанокристаллами скорость $k$ передачи возбуждения от TPD к нанокристаллам уменьшается по закону $k \sim d^{-6.8 \pm 2.7}$, что свидетельствует о ферстеровском механизме; оцененный ферстеровский радиус составил 3.9 нм.

Работа выполнена при финансовой поддержке грантами РФФИ № 16-02-00594, 16-32-00426 мол_а и $15-02-05856 \mathrm{a}$, а также грантом президента РФ № МK-7514.2015.2.

\section{Список литературы}

[1] C.B. Murray, D.J. Norris, M.G. Bawendi. J. Am. Chem. Soc., 115, 8706 (1993).

[2] J. Lim, W.K. Bae, J. Kwak, S. Lee, C. Lee, K. Char. Optical Mater. Express, 2, 594 (2012).

[3] S. Coe, W.-K. Woo, M. Bawendi, V. Bulović. Nature, 420, 800 (2002).

[4] A.A. Vashchenko, V.S. Lebedev, A.G. Vitukhnovskii, R.B. Vasiliev, I.G. Samatov. JETP Lett., 96, 113 (2012).

[5] S. Ren, L.-Y. Chang, S.-K. Lim, J. Zhao, M. Smith, N. Zhao, V. Bulović, M. Bawendi, S. Gradečak. Nano Lett., 113998 (2011).

[6] G. Konstantatos, M. Badioli, L. Gaudreau, J. Osmond, M. Bernechea, F.P.G. de Arquer, F. Gatti, F.H.L. Koppens. Nature Nanotechnology, 7, 363 (2012).

[7] C. Dang, J. Lee, C. Breen, J.S. Steckel, S. Coe-Sullivan, A. Nurmikko. Nature Nanotechnology, 7, 335 (2012).

[8] P.O. Anikeeva. Physical Properties and Design of LightEmitting Devices Based on Organic Materials and Nanoparticles (Ph.D Thesis, Massachusetts Institute of Technology. Dept. of Materials Science and Engineering, 2009).

[9] N.S. Kurochkin, A.A. Vashchenko, A.G. Vitukhnovsky, P.N. Tananaev. Semiconductors, 49 (7), 953 (2015).

[10] G.M. Akselrod, F. Prins, L.V. Poulikakos, E.M.Y. Lee, M.C. Weidman, A.J. Mork, A.P. Willard, V. Bulović, W.A. Tisdale. Nano Lett., 14, 3556 (2014).

[11] M. Anni, L. Manna, R. Cingolani, D. Valerini, A. Creti, M. Lomascolo. Appl. Phys. Lett., 85 (18), 4169 (2004).

[12] J.Z. Niu, H. Shen, C. Zhou, W. Xu, X. Li, H. Wang, S. Lou, Z. Du, L.S. Li. Dalton Transactions, 39 (13), 3308 (2010).

[13] J. Jasieniak, L. Smith, J. van Embden, P. Mulvaney, M. Califano. J. Phys. Chem. C, 113, 19468 (2009).

[14] V. Agranovich, M. Galanin. Electronic Excitation Energy Transfer in Condensed Matter (Modern problems in condensed matter sciences) (Amsterdam-N.Y.-Oxford, North-Holland, 1982).

\section{Energy transfer from TPD to CdSe/CdS/ZnS colloidal nanocrystals}

\author{
N.S. Kurochkin ${ }^{1,2}$, A.V. Katsaba ${ }^{1,3}$, \\ S.A. Ambrozevich 1,3, A.G. Vitukhnovsky ${ }^{\mathbf{1 , 2}}$, \\ A.A. Vashchenko ${ }^{1}$, P.N. Tananaev ${ }^{4}$ \\ ${ }^{1}$ Lebedev Physical Institute, \\ Russian Academy of Sciences, \\ 119991 Moscow, Russia \\ ${ }^{2}$ Moscow Institute of Physics and Technology \\ (State University), \\ 141700 Dolgoprudny, Russia \\ ${ }^{3}$ Bauman Moscow State Technical University, \\ 125993 Moscow, Russia \\ 4 Dukhov VNIIA, \\ 101000 Moscow, Russia
}

Abstract We studied the efficiency of energy transfer from TPD organic semiconductor to $\mathrm{CdSe} / \mathrm{CdS} / \mathrm{ZnS}$ nanocrystals passivated with different organic ligands. It was demonstrated that the energy transfer rate from TPD to nanocrystals is decreased when the thickness of nanocrystal capping layer is increased. The Förster mechanism was suggested to be responsible for the energy transfer observed.

Редактор Г.А. Оганесян 